New therapies

\title{
Pulmonary embolism - the role of thrombolytic therapy in its management
}

\author{
Ranjit S More, Anoop Chauhan
}

\section{Summary}

In massive pulmonary embolism where there may be evidence of right ventricular dysfunction and acute pulmonary hypertension, anticoagulation therapy alone may prove inadequate. In such situations use of thrombolytic agents produces an improvement in haemodynamics compared to anticoagulants alone, although studies to date have been too small to address the isssue of mortality benefit. It would appear that all age groups gain benefit from the use of thrombolytics. Studies that have compared thrombolytic agents and anticoagulants are discussed. In addition, the issues of the choice of thrombolytic agent and the different modes of delivery of therapy are addressed.

Keywords: pulmonary embolism, thrombolysis, anticoagulation

Academic Department of Cardiology, St Mary's Hospital, London W2 1NY, UK

RS More

Department of Cardiology, Papworth Hospital, Cambridge, UK

A Chauhan

Accepted 14 August 1995
Pulmonary embolism is a commonly encountered disorder, often precipitated by deep venous thrombosis. Venous thromboembolism is the third most common cardiovascular disorder after acute coronary syndromes and stroke, with 300000 hospitalisations and 50000 deaths annually in the US alone. ${ }^{1}$ The true incidence is probably much higher with many cases going undiagnosed. It can result in pulmonary hypertension and right ventricular dysfunction and has a mortality rate of approximately $14 \% .^{2}$

\section{Diagnosis}

The diagnosis can frequently be made on the basis of the clinical presentation. This usually involves an acute onset of pleuritic pain associated with shortness of breath and perhaps haemoptysis. A preceding history of deep venous thrombosis may be present. The patient usually has a tachycardia, is tachypnoeic and may be hypoxic and hypotensive. Depending on the size of the pulmonary embolus the electrocardiogram may show transient features of acute right heart strain with right axis deviation and right bundle branch block. ${ }^{3}$ In addition the frequently quoted $S_{1} Q_{3} T_{3}$ changes may be evident. The diagnosis can usually be confirmed by ventilation/perfusion scans (a ventilation/perfusion mismatch being indicative of a pulmonary embolus) or pulmonary angiography (the 'gold standard' see figure). Other possible means of confirming the diagnosis include the use of echocardiography (including transoesphageal echocardiography) to detect thrombus directly in the pulmonary trunk and proximal parts of each pulmonary artery. ${ }^{4}$

\section{Consequences of pulmonary embolism}

The haemodynamic response to pulmonary embolism depends upon a number of factors including the size of the embolus, any coexistent cardiopulmonary disease, and the neurohumeral responses produced. An acute increase in right ventricular afterload occurs when approximately $25 \%$ of total pulmonary blood flow is acutely obstructed. ${ }^{5}$ Although right ventricular systolic pressure continues to rise as the degree of obstruction increases it is usually unable to generate a maximum mean pulmonary artery pressure above $30 \mathrm{mmHg}$. $^{5}$ Thus as afterload continues to increase, the right ventricle begins to fail and right atrial pressure rises; when forward cardiac output can no longer be sustained clinical shock occurs. Acute mortality correlates with the presence of systemic hypotension, implying that right heart functional reserve is the major determinant of acute survival. ${ }^{6}$ Longer term mortality, however, is dependent to a major degree on co-existent cardiopulmonary disease. ${ }^{7}$

\section{Treatment}

Standard therapy in the past consisted of anticoagulation, initially with intravenous heparin and subsequently with warfarin. Barritt and Kordan first reported on the mortality benefit of anticoagulation in pulmonary embolism. They observed no deaths in 54 patients treated with anticoagulants (intravenous heparin over 36 hours and nicoumalone for 14 days) whilst there were five deaths in 19 control patients who did not receive any anticoagulants. ${ }^{8}$ The rationale for anticoagulation is to provide prophylaxis against further thromboembolic events during the period of time that the body's own fibrinolytic system is gradually lysing the embolus. ${ }^{5}$ In contrast, the theory behind the use of thrombolytic therapy (followed by anticoagulation) for pulmonary embolism is that thrombolysis, by actively dissolving formed clot, would restore cardiopulmonary function to normal more quickly. In addition chronic pulmonary hypertension may also be reduced and the source of embolus in the venous system may be 


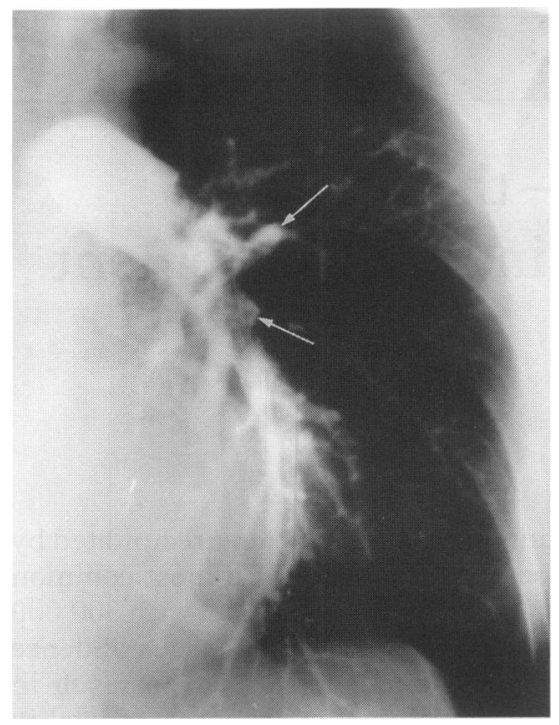

Figure Pulmonary angiogram obtained using a pulmonary artery catheter. Multiple intraluminal clots are present (arrows) in the left upper and lower lobe pulmonary arteries

\begin{tabular}{|l|}
\hline $\begin{array}{l}\text { Management options in } \\
\text { pulmonary embolism }\end{array}$ \\
\hline - conventional anticoagulation - iv \\
heparin followed by warfarin for 3 \\
months \\
- thrombolytic therapy \\
(streptokinase, urokinase or tPA) \\
followed by anticoagulation \\
pulmonary embolectomy \\
\hline
\end{tabular}

Box 1

\begin{tabular}{|l|}
\hline $\begin{array}{l}\text { Indications for } \\
\text { thrombolytic therapy }\end{array}$ \\
\hline - massive pulmonary embolism - as \\
first line therapy \\
failure of patient to respond to a \\
conventional anticoagulation \\
regime
\end{tabular}

Box 2 removed or reduced. ${ }^{6}$ Thrombolysis would thus be particularly beneficial in massive pulmonary embolism associated with haemodynamic compromise. The only alternative treatment available for such patients previously would have been pulmonary embolectomy, a procedure available in only a limited number of hospitals.

In patients with major pulmonary embolism, anticoagulation alone may fail to resolve pulmonary artery clot completely in $75 \%$ of patients at $1-4$ weeks, and in $50 \%$ at four months. ${ }^{9,10}$ The thrombolytic agents urokinase and streptokinase were first approved for the treatment of pulmonary embolism in 1977. Urokinase was approved in a dose of $2000 \mathrm{U} / \mathrm{lb}$ as a bolus followed by $2000 \mathrm{U} / \mathrm{lb}$ hourly for 12 to $24 \mathrm{~h}$, whilst streptokinase was approved as a fixed bolus of $250000 \mathrm{U}$ followed by $100000 \mathrm{U} / \mathrm{h}$ for $24 \mathrm{~h} .{ }^{11}$ Several small early uncontrolled studies showed that streptokinase delivered either locally via a pulmonary artery catheter or peripherally appeared to produce angiographic and clinical improvement. ${ }^{12-14}$ The doses used varied with an initial bolus (over $15-60 \mathrm{~min}$ ) of $160000-600000 \mathrm{U}$ and a maintenance infusion of $90000-150000 \mathrm{U}$ for up to $72 \mathrm{~h}$. A number of different dosage regimes of urokinase have been reported to be effective in producing haemodynamic and angiographic improvement ${ }^{15-17}$ including low-dose short infusions of urokinase (200000-300 $000 \mathrm{U}$ over two hours given to nine patients, which resulted in good clinical response in seven of them). ${ }^{18}$

\section{THROMBOLYSIS vs ANTICOAGULATION}

Although there have been several clinical studies comparing thrombolytic therapy and anticoagulants alone, these studies had limited patient numbers. All the early studies demonstrated a more rapid anatomical or physiological improvement in thrombolysis-treated patients, but because of the small sample sizes the effects on mortality could not be determined. ${ }^{19-23}$

One of the larger early studies, the phase I portion of the Urokinase Pulmonary Embolism Trial (UPET), compared heparin alone with urokinase (12 h infusion) in 160 patients with angiographically proven pulmonary embolism. ${ }^{19}$ Although $24 \mathrm{~h}$ post-commencement of therapy the urokinase-treated group had significantly greater haemodynamic and anatomical improvements than the heparin-treated patients, by five to seven days post-treatment no difference between the two groups was noted on lung scans. In addition, during the two weeks following therapy, there was a trend towards fewer recurrent pulmonary emboli in the urokinase-treated patients $(17 \%$ vs $23 \%$ ). The benefits of thrombolytic therapy, however, were achieved at a cost, namely increased bleeding complications $(27 \%$ incidence of severe bleeding, defined as a fall in haematocrit of more than $10 \%$ and/or need for a blood transfusion of more than two units). Small studies that utilised either centrally or peripherally administered streptokinase showed evidence of increased thrombolysis both clinically and angiographically when compared to heparin administration alone. ${ }^{20,21,24}$

Two early small studies (13 and 15 patients) which compared heparin alone with tissue plasminogen activator (tPA), 25-80 mg given over 40-90 min, plus heparin, noted a modest early improvement in total pulmonary resistance and arterial oxygen saturations in the tPA-treated patients. However, pulmonary angiograms two hours post-treatment showed no significant difference and lung scans 24-h post-treatment only showed a trend towards greater improvement with tPA. ${ }^{25,26}$ In the PAIMS 2 study 36 patients were randomised to a two-hour infusion of recombinant $\mathrm{PPA}$ ( $\mathrm{rtPA}$ ) followed by heparin, versus heparin alone. ${ }^{27}$ The mean pulmonary artery pressure at two hours decreased significantly in the rtPA plus heparin group but not in the heparin alone group. Lung scans at days 7 and 30, however, were not dissimilar in the two groups. In a larger, more recent, study Goldhaber and colleagues randomised 101 haemodynamically stable patients with pulmonary embolus such that 46 received rtPA ( $100 \mathrm{mg}$ over two hours) and 55 heparin alone. ${ }^{28}$ In $39 \%$ of rtPA-treated patients (cf $17 \%$ of the heparin-treated group) right ventricular wall motion improved at $24 \mathrm{~h}$. Pulmonary perfusion also improved by $14.6 \%$ compared to $1.5 \%$. No clinical episodes of recurrence occurred in their rtPA group whereas five of the heparin group had recurrent episodes within 14 days. ${ }^{28}$

\section{THE ROLE OF tPA}

Experimental studies of venous thromboembolism which appeared to suggest that tPA was more potent than urokinase or streptokinase prompted the clinical assessment of tPA in pulmonary embolism. ${ }^{29,30} \mathrm{tPA}$ use in venous thrombosis was first reported in $1981,{ }^{31}$ and its use in pulmonary embolism in $1985 .{ }^{32} \mathrm{~A}$ 65 -year-old man received $30 \mathrm{mg}$ of rtPA over 90 minutes via a catheter inserted into the right ventricle. Pulmonary angiography 90 minutes later demonstrated 


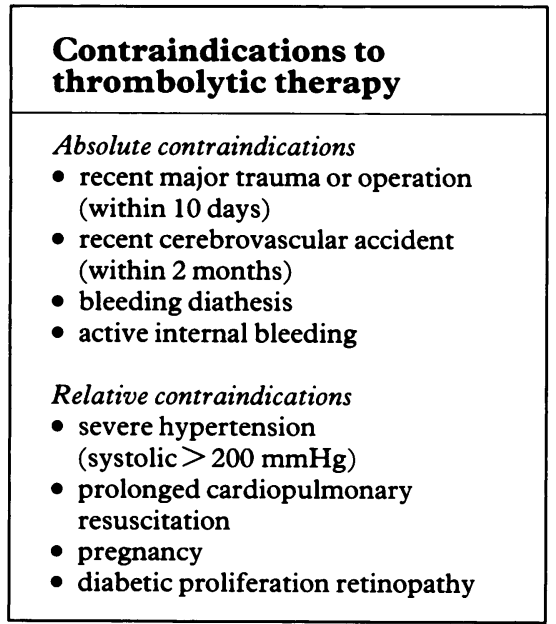

Box 3 recanalisation. In 1986, Braunwald's group reported on 30 patients with angiographically proven pulmonary embolism (segmental or more proximal pulmonary artery involved) presenting within five days of onset of initial symptoms. ${ }^{33}$ These individuals received $50 \mathrm{mg}$ of rtPA peripherally over two hours. Pulmonary angiography was repeated immediately after completion of the infusion. If significant clot lysis was evident then routine measures including anticoagulation were continued. If no significant clot lysis was seen, an additional $40 \mathrm{mg}$ of rtPA was administered over four hours with repeat angiogram. Overall 28 patients had evidence of clot lysis after treatment with rtPA with qualitative improvement noted by $83 \%$. Mean pulmonary artery pressures decreased significantly from 21 to $18 \mathrm{mmHg}$ and right ventricular dysfunction on echocardiography resolved rapidly in some patients. Only one of the treated patients had major bleeding complications. The US Food and Drug Administration approved use of rtPA for acute pulmonary embolism (100 mg given intravenously over two hours) in 1990.

\section{COMPARISON OF THROMBOLYTIC AGENTS}

Only limited information is available comparing different thrombolytic agents in the treatment of pulmonary embolism. In the phase II portion of UPET, regimes comprising $12 \mathrm{~h}$ of urokinase, $24 \mathrm{~h}$ of urokinase, or $24 \mathrm{~h}$ of streptokinase $(250000 \mathrm{U}$ bolus and $100000 \mathrm{U} / \mathrm{h}$ for $24 \mathrm{~h}$ ) were compared in 167 patients. No differences in mortality or angiographic resolution were noted in the three groups. ${ }^{34}$

Goldhaber et al conducted a randomised study of 90 patients comparing $100 \mathrm{mg}$ rtPA (over two hours) with urokinase $\left(3 \times 10^{6} \mathrm{U}\right.$ over two hours, with the initial $1 \times 10^{6} \mathrm{U}$ given as a bolus over $\left.10 \mathrm{~min}\right){ }^{35}$ Both drugs were administered peripherally and all the recruited cases had angiographically proven pulmonary embolism. In 87 patients repeat pulmonary angiograms were available at two hours. In the rtPA group $79 \%$ showed angiographic improvement compared to $67 \%$ of the urokinase group but this difference was not significant. Furthermore perfusion lung scans at 24 hours were similar in the two groups. The European Cooperative Study Group for Pulmonary Embolism assessed 63 patients randomised to urokinase $(4400 \mathrm{U} / \mathrm{kg}$ bolus, $4400 \mathrm{U} / \mathrm{kg}$ hourly for $12 \mathrm{~h}$ ) or rtPA (10 mg bolus, $90 \mathrm{mg}$ over two hours) followed by heparin. ${ }^{36}$ The decrease in total pulmonary resistance at $12 \mathrm{~h}$ was similar in the two groups (53\% and $48 \%$, respectively). Bleeding complications were also similar in the two groups.

\section{BOLUS REGIMES}

Animal experiments have previously shown that thrombolysis continues for some time after tPA is cleared from the circulation and that thrombolysis can be accelerated and increased with reduced bleeding if tPA is administered over a short period. ${ }^{37}$ In a study of bolus therapy 58 patients were randomised to receive either a two-minute infusion of $\mathrm{rtPA}(0.6 \mathrm{mg} / \mathrm{kg})$ or saline placebo in addition to a standard heparin infusion regime. ${ }^{38}$ Of the actively treated patients $34 \%$ had a greater than $50 \%$ resolution in perfusion defects at $24 \mathrm{~h}$ compared to only $12 \%$ of the placebo-treated group. However, this difference was no longer apparent in lung scans carried out at seven days. No major bleeding complications were noted in the rtPA-treated patients.

In a prospective open trial, 54 patients with massive pulmonary embolism received a 10-min infusion of rtPA at a dose of $1 \mathrm{mg} / \mathrm{kg}$. At $48 \mathrm{~h}$ and 10 days there was an absolute improvement in the perfusion defect of $11 \%$ and $31 \%$, respectively. ${ }^{39}$ One of the patients died of an intracranial haemorrhage.

Published studies of bolus regimes using urokinase or streptokinase are few in number. Two small open studies that used boluses of $15000 \mathrm{U} / \mathrm{kg}$ and $20000 \mathrm{U} / \mathrm{kg}$ of urokinase observed both angiographic improvement and a reduction of pulmonary artery pressure, with a low incidence of major bleeding complications. ${ }^{40-41}$ There are, however, no published studies to date comparing bolus and other administration regimes.

\section{LOCAL THERAPY}

Thrombolytic therapy can be administered centrally rather than peripherally, using catheters sited in either the right ventricle or in the pulmonary circulation itself. In theory this should result in higher local concentrations of thrombolytic agent at the site of the pulmonary embolus and may minimise bleeding complications. Several of the early studies that used streptokinase involved locally delivered therapy over several hours (up to $72 \mathrm{~h}$ ). ${ }^{12-14,24,42}$ In a nonrandomised study of 10 patients with massive pulmonary embolus, treatment comprised intrapulmonary thrombolytic therapy (urokinase or streptokinase), anticoagulation and Greenfield filters. ${ }^{43} \mathrm{~A}$ rapid response was seen in all with 
significant improvements in oxygen saturation, pulmonary artery pressures, cardiac output and blood pressure compared to 10 comparable patients over the same time period who had received heparin alone. Low-dose streptokinase $(10000 \mathrm{U} / \mathrm{h}$ for $15-30 \mathrm{~h})$ delivered locally may also produce rapid lysis. ${ }^{44}$

In a brief recent report three patients with massive pulmonary embolism that were treated with centrally administered tPA all responded with rapid improvement of pulmonary artery pressures, and marked reduction of chest pain and shortness of breath. ${ }^{45}$ However, Verstraete and colleagues, who compared peripheral intravenous versus local pulmonary administration of rtPA in 34 patients, noted that local pulmonary delivery did not appear to confer any advantage. Similar rates of lysis, bleeding and induction of systemic lytic state were observed. ${ }^{46}$

\section{SPECIAL CASES}

Special protocols which theoretically allow more gradual thrombolysis have been suggested for treating massive pulmonary embolus in patients who have undergone recent surgery. One group has suggested a regime comprising of a bolus of urokinase $(2200 \mathrm{U} / \mathrm{kg})$ injected directly into the clot via a catheter positioned in the pulmonary artery, to be followed by a continuous infusion of urokinase at $2200 \mathrm{U} / \mathrm{kg}$ hourly until the clot is lysed (infusion duration up to a maximum of $24 \mathrm{~h}){ }^{47}$ Heparin is administered simultaneously via a peripheral vein at $500 \mathrm{U} / \mathrm{h}$. However, there are no comparative data or studies with more conventional thrombolytic regimes to suggest that regimes similar to the one described above are any safer. Adjuvant measures to thrombolysis, such as cardiopulmonary bypass, may have a role to play in the treatment of specific patients with massive pulmonary embolus who present with cardiac arrest. ${ }^{48}$

From the studies carried out to date thrombolytic therapy (whether it be streptokinase, urokinase or tPA) appears to be effective in all age groups for the treatment of massive pulmonary embolism. Elderly patients (ie, $>70$ years) gained similar benefits to younger patients without an increased incidence of major bleeding complication ${ }^{49}$ when streptokinase was administered in a regime comprising $250000 \mathrm{U}$ over $15 \mathrm{~min}$ and an infusion of $100000 \mathrm{U} / \mathrm{h}$ for $12 \mathrm{~h}$.

\section{Conclusion}

\section{Summary/learning points}

- patients with massive pulmonary embolism should all be considered for thrombolytic therapy

- all age groups benefit from thrombolytic therapy

- peripheral administration of thrombolytic therapy is effective

- short duration regimes are as effective as longer duration regimes

- no apparent major difference in efficacy of the different thrombolytic agents

\section{Box 4}

1 Gillum RF. Pulmonary embolism and thrombophlebitis in the United States, 1970-1985. Am Heart F 1987; 114: 1262-4

2 Wessler S. Prevention of venous thromboem bolism: rationale, practice, and problems. NIH 1986 Consensus Development Conference on Prevention of Venous Thrombosis and Pulmonary Embolism, National Institutes of Health, Bethesda, Maryland, 1986.

3 Miller GAH. Pulmonary embolism. In: Weatherall DJ, Ledingham JGG, Warrell DA erall DJ, Ledingham JGG, Warrell DA,
eds.Oxford textbook of medicine. Oxford: Oxford eds.Oxford textbook of medicine. Oxford:

4 Gelernt MD, Mogtader A, Hahn RT. Transoesphageal echocardiography to diagnose and demonstrate resolution of an acute massive pulmonary embolus. Chest 1992; 102: 297-9.

5 Goldhaber SZ, Braunwald E. Tissue plasminogen activators in the treatment of acute pulmonary embolism. In: Sobel BE, Collen D, Grossbard EB, eds. Tissue plasminogen activator in thrombolytic therapy. Basel: Marcel Dekker Inc, 1987; pp 147-69.

6 Porter RS, Dipalma JR. Thrombolysis for pulmonary embolism. Am Fam Physician 1991; 44 1365-70.

7 Heitz JA. An analysis of current pulmonary embolism therapy. Int Angiol 1992; 11: 57-63.

Thrombolytic therapy should be considered in all patients with massive pulmonary embolism where there may be evidence of acute pulmonary hypertension, right ventricular dysfunction and possibly systemic hypotension. Although the studies to date have been too small to address the issue of mortality benefit there does appear to be objective evidence of haemodynamic benefit over that achieved by anticoagulation alone. Thrombolysis also apparently reduces the incidence of early recurrence of pulmonary embolism. All age groups and postoperative patients also seem to benefit. Bolus and front-loaded regimes (ie, administered over two or less hours) are simpler to use and appear as effective as longer duration regimes. There does not appear at this stage to be any major difference in efficacy between the different thrombolytic agents. Streptokinase should be avoided in those individuals who have received it previously for whatever indication, because of the likely presence of neutralisation antibodies. ${ }^{50}$

8 Barritt DW, Jordan SC. Anticoagulant drugs in the treatment of pulmonary embolism. Lancet 1960; 1: 1309-12

9 Daleen JE, Banas JS, Brooks HC, et al. Resolution rate of acute pulmonary embolism in man. N Engl f Med 1969; 280: 1194-8.

10 Tow DE, Wagner NH. Recovery of pulmonary artery flow in patients with pulmonary emboartery flow in patients with pulmonary
lism. $N$ Engl $₹$ Med 1967; 276: 1053-6.

11 Thrombolytic therapy in thrombosis: a National Institutes of Health consensus development Institutes of Health consensus development

12 Hirsh J, Hale GS, McDonald TG, McCarthy Hirsh J, Hale GS, McDonald TG, McCarthy
RA, Pitt A. Streptokinase therapy in acute major pulmonary embolism: effectiveness and probpulmonary embolism: effecti

13 Kakkar VV, Raftery EB. Selection of patients with pulmonary embolism for thrombolytic therapy. Lancet 1970; 2: 237-41.

14 Miller GA, Sutton GC, Kerr IH, Gibson RV Honey $M$. Comparison of streptokinase and heparin in treatment of isolated acute massive pulmonary embolism. BMF 1971; 2: 681-4.

15 Urokinase-Streptokinase Embolism Trial Phas II results. A cooperative study. $\mathcal{F} A M A 1974$; 229: $1606-13$.
16 The UKPE study. Multicentre clinical trial on two local regimens of urokinase in massive pulmonary embolism. Eur Heart $f$ 1987; 8: $2-10$.

17 Griguer P, Charbonnier B, Latour F, Fauchier JP, Brochier M. Plasminogen and moderate doses of urokinase in the treatment of acute doses of urokinase in the treatment of acute
pulmonary embolism. Angiology 1979; 30: pulmonar.

18 Edwards IR, MacLean KS, Dow JD. Low dose urokinase in major pulmonary embolism. Lancet 1973; 2: 409-13.

19 The Urokinase Pulmonary Embolism Trial Study Group. The Urokinase Pulmonary Embolism Trial: a national cooperative study. Circulation 1973; 47/48(suppl II): II-1-108.

20 Hirsh J, McDonald IG, Hale GA, et al. Comparison of the effects of streptokinase and heparin in the early rate of resolution of major pulmonary embolism. Can Med Assoc $\mathcal{F} 1971$; 104: 488-91.

21 Sharma GVRK, Burleson VA, Sasahara AA. Effect of thrombolytic therapy on pulmonarycapillary blood volume in patients with pulmonary embolism. $N$ Engl $f$ Med 1980; 303: 842-5. 
22 Tibbutt DA, Davies JA, Anderson JA, et al. Comparison by controlled clinical trial of streptokinase and heparin in the treatment of life tokinase and heparin in the treatment of life threatening 743 .

23 Ly B, Arnesen H, Eie H, Hol R. A controlled clinical trial of streptokinase and heparin in the treatment of major pulmonary embolism. Acta Med Scand 1978; 203: 465-70.

24 Tibbutt DA, Davies JA, Miller GA, et al. Comparison between streptokinase and heparin in life-threatening pulmonary embolism. $\mathrm{Br} \mathcal{F}$ Haematol 1973; 25: 275-6.

25 The PIOPED Investigators. Tissue plasminogen activator for the treatment of acute pulmonary embolism. A collaborative study by 528-33.

26 Yamasawa F, Okada Y, Asano K, Mori M, Fujita H, Hasegawa N. The role of recombinant human tissue type plasminogen activator in the human tissue type plasminogen activator in the treatment of acute pulmonary thr
bolism. Intern Med 1992; 31: 885-8.

27 Dalla-Volta S, Palla A, Santolicandro A, et al. PAIMS 2: alteplase combined with heparin versus heparin in treatment of acute pulmonary embolism. Plasminogen Activator Italian Multicenter Study 2. $\mathcal{F}$ Am Coll Cardiol 1992; 20: 520-6.

28 Goldhaber SZ, Haire WD, Feldstein ML, et al. Alteplase versus heparin in acute pulmonary embolism: randomised trial assessing right ventricular function and pulmonary perfusion. Lancet 1993; 341: 507-11.

29 Korninger C, Matsuo O, Suy R, Stassen JM, Collen D. Thrombolysis with human extrinsic (tissue type) plasminogen activator in dogs with femoral vein thrombosis. $\mathcal{f}$ Clin Invest 1983; 71: 368-76.

30 Agnelli G, Buchanan MR, Fernandez F, et al. A comparison of the thrombolytic and haemorrhagic effects of tissue type plasminogen activator and streptokinase in rabbits. Circulation 1985; 72: 178-82.
31 Weimar W, Stibbe J, van Seyen AJ, Billiau A, DeSomer P, Collen D. Specific lysis of an iliofemoral thrombus by administration of extiliofemoral thrombus by administration of extrinsic (tissue type) plasm
Lancet 1981; 2: 1018-20.

32 Bounameaux H, Vermylen J, Collen D. Thrombolytic treatment with recombinant tissue-type plasminogen activator in a patient with massive pulmonary embolism. Ann Intern Med 1985; 103: 64-6.

33 Goldhaber SZ, Vaughan DE, Markis JE, et al. Acute pulmonary embolism treated with tissue plasminogen activator. Lancet 1986; 2: 886-9.

34 Bell WRE, Simon TL, Stengle JM, Sherry S. The urokinase-streptokinase pulmonary embolism trial (phase II) results. Circulation 1974; 50: 1070-1.

35 Goldhaber SZ, Kessler CM, Heit JA, et al. Recombinant tissue type plasminogen activator versus a novel dosing regimen of urokinase in acute pulmonary embolism: a randomised controlled multicenter trial. $¥ \mathrm{Am}$ Coll Cardiol 1992; 20: $24-30$.

36 Meyer GM, Sors H, Charbonnier B, et al on behalf of The European Cooperative Study Group for Pulmonary Embolism. Effects of intravenous urokinase versus alteplase on total pulmonary resistance in acute massive pulmonary embolism: a European multicentre double-blind trial. ₹ Am Coll Cardiol 1992; 19: 239-45.

37 Levine MN. Bolus, front-loaded, and accelerated thrombolytic infusions for myocardial infarction and pulmonary embolism. Chest 1991; 99 (suppl 4): 128S-34S.

38 Levine $M$, Hirsh J, Weitz J, et al. A randomised trial of a single bolus dosage regimen of recombinant tissue plasminogen activator in patients with acute pulmonary embolism. Chest 1990; 98: with acute $1473-9$.

39 Diehl JL, Meyer G, Igual J, et al. Effectiveness and safety of bolus administration of alteplase in massive pulmonary embolism. Am $\mathcal{f}$ Cardiol 1992; 70: 1477-80.
40 Petitpretz P, Simmoneau G, Cerrina J, et al. Effects of a single bolus of urokinase in patients with life-threatening pulmonary emboli: a descriptive trial. Circulation 1984; 70: 861-6.

41 Stern M, Meyer G, Sors H. Urokinase versus tissue plasminogen activator in pulmonary embolism (letter). Lancet 1988; 2: 691-2.

42 Mavor GE, Harper DR, Woodruff PW. Treatment of massive pulmonary embolism (letter) BMF 1973; 1: 175-6.

43 Rosenthal D, Evans E, Borrero E, Lamis PA, Clark MD, Daniel WW. Massive pulmonary embolism: triple armed therapy. $f$ Vasc Surg 1989; 9: 261-70

44 Vujic I, Young JW, Gobien RP, Dawson WT, Liebscher L, Shelley BE. Massive pulmonary embolism: treatment with full heparinisation and topical low-dose streptokinase. Radiology 1983; 148: $671-5$.

45 Mohindra SK, Udeani GO. Treatment of massive pulmonary embolism with centrally administered tissue type plasminogen activator. $A n n$

46 Verstraete M, Miller GAH, Bounameaux H, et al. Intravenous and intrapulmonary recombinant tissue type plasminogen activator in the treatment of acute massive pulmonary embolism. Circulation 1988; 77: 353-60.

47 Molina JE, Hunter DW, Yedlicka JW. Thrombolytic therapy for postoperative pulmonary embolism. Am f Surg 1992; 163: 375-80.

48 Frizelle FA, Massey R, Feint JA, Xabregas AA. Tissue plasminogen activator and cardiopulmonary bypass for massive pulmonary embolus. Aust NZ $\mathcal{J}$ Surg 1991; 61: 151-3.

49 Meneveau N, Bassand JP, Schiele F, et al. Safety of thrombolytic therapy in elderly patients with massive pulmonary embolism: a comparison with nonelderly patients. $\boldsymbol{F}$ Am Coll Cardiol 1993; 22: 1075-9.

50 Gemmill JD, Hogg KJ, Dunn FG, Rae AP, Hillis WS. Pre-dosing antibody levels and efficacy of thrombolytic drugs containing streptokinase. $\mathrm{Br}$ Heart $\mathcal{F}$ 1994; 72: 222-5. 